\title{
Statement on folic acid: fortification and supplementation
}

Serious congenital abnormalities occur in 2 to $3 \%$ of live births and neural tube defects, cleft lip and palate, and cardiac abnormalities are some of the most common. There is now substantial evidence that periconceptual folic acid will reduce the incidence of neural tube defects by more than $50 \%$ and may also decrease the incidence of other malformation.

Regulations recently enacted by the Food and Drug Administration will require the fortification of enriched grain foods with folic acid starting some time in 1998. While this is a step forward, the actual amount added may be insufficient to protect future children.

The American College of Medical Genetics strongly supports the FDA's action. In addition, however, it recommends the following:

1. Foods should be fortified with folic acid at levels increased from current FDA recommendations of 0.14 to $0.28 \mathrm{mcg} / 100 \mathrm{~g}$ of grain.

2. Women in their reproductive years should take an additional $0.4 \mathrm{mg}$ of folic acid daily, either alone or in a multivitamin preparation. This is particularly important prior to conception.

3. Women with a previous history of neural tube defects are advised to take $4.0 \mathrm{mg}$ of folic acid daily starting at least one month and preferably three months prior to conception.

4. Adults should be advised of the benefits of folic acid supplementation to reduce the risk of cardiovascular disease.

5. Because of a potential concern of masking timely detection of B12 deficiency, the total daily intake of folic acid should not exceed $1.0 \mathrm{mg}$ unless prescribed by a physician.

Revised and approved by the ACMG Executive Committee on February 28, 1997.

CAmerican College of Medical Genetics, 1997

AMERICAN COLLEGE OF MEDICAL GENETICS

9650 Rockville Pike

Bethesda, Maryland 20814-3998

Phone: 301-530-7127

Fax: 301-571-1895

This guideline is designed primarily as an educational resource for medical geneticists and other health care providers to help them provide quality medical genetic services. Adherence to this guideline does not necessarily assure a successful medical outcome. This guideline should not be considered inclusive of all proper procedures and tests or exclusive of other procedures and tests that are reasonably directed to obtaining the same results. In determining the propriety of any specific procedure or test, the geneticists should apply his or her own professional judgment to the specific clinical circumstances presented by the individual patient or specimen. It may be prudent, however, to document in the patient's record the rationale for any significant deviation from this guideline. 